\title{
La brecha entre las prácticas de los docentes y las percepciones estudiantiles sobre la educación religiosa en Costa Rica
}

\author{
The gap between teacher practices and student \\ perceptions about religious education in Costa Rica
}

\section{Laura Fuentes Belgrave \\ Universidad Nacional de Costa Rica}

\begin{abstract}
Resumen
Este artículo comparte algunos de los principales resultados de una investigación (2015-2017), que compara las prácticas docentes en la asignatura costarricense de educación religiosa con las percepciones y expectativas del estudiantado de tercer ciclo y de educación diversificada sobre esta materia. En el estudio se identifica y analiza la enseñanza y el aprendizaje de temas generadores, metas y actividades de comprensión de índole educativa, así como elementos del contexto socio-cultural de Costa Rica, a través de un enfoque mixto que mide cuantitativamente las respuestas de los docentes obtenidas mediante sondeo, y valora cualitativamente los testimonios estudiantiles recolectados a través de grupos focales.
\end{abstract}

Palabras clave: Educación religiosa, catolicismo, interculturalidad, interreligiosidad, Costa Rica

\begin{abstract}
This article shares some of the main results of an investigation (2015-2017), that compares the teaching practices in the Costa Rican subject of religious education with the perceptions and expectations of students in the third cycle and diversified education on this subject. The study identifies and analyzes the teaching and learning of generating themes, goals and comprehension activities of an educational nature, as well as elements of the socio-cultural context of Costa Rica, through a mixed approach that quantitatively measures the responses of the teachers obtained through surveys, and qualitatively assess student testimonies collected through focus groups.
\end{abstract}

Keywords: Religious education, Catholicism, interculturality, interreligiousness, Costa Rica 
Ante la incógnita del tipo de prácticas que desarrollan los docentes en el campo de la educación religiosa y la forma en que estas son percibidas por el estudiantado, este artículo se propone examinar esta problemática, a partir de la investigación realizada desde la Escuela Ecuménica de Ciencias de la Religión de la Universidad Nacional entre 2015 y 2017. Cantar, rezar y colorear son las palabras textuales de jóvenes estudiantes entrevistados para esta investigación, quienes definen con estos verbos las prácticas docentes de las que han sido sujetos desde la primaria, en contraste tanto con las actividades pedagógicas sugeridas por los programas educativos, como con las afirmaciones del profesorado.

Este estudio, de enfoque mixto, buscó responder al objetivo general de explorar el vínculo entre las prácticas de la educación religiosa en la población docente que imparte esta asignatura, y las percepciones que tiene sobre ellas el estudiantado de tercer ciclo y de educación diversificada del sistema educativo costarricense. Tanto desde una perspectiva cuantitativa como cualitativa, se trabajó sobre cuatro objetivos de investigación, donde el primero fue: identificar los temas generadores, metas y actividades de comprensión utilizados en las clases de religión por la población docente. Para lograr esto, se analizaron los programas educativos actuales y se realizó una investigación bibliográfica de antecedentes sobre la educación religiosa en Costa Rica, la cual dio cuenta de la colonización católica de imaginarios que históricamente ha impuesto este tipo de educación, así como de la readecuación educativa posterior al II Concilio Vaticano, los puntos de giro del siglo XXI, así como de las investigaciones realizadas sobre el personal docente, el estudiantado y la formación religiosa, cuyo sello es indudablemente catequístico.

Esta huella indeleble cuaja en las transformaciones posteriores de los programas de educación religiosa para tercer ciclo y educación diversificada, que como se observa en el siguiente esquema, sufren cambios más nominales que substanciales, cuyo contenido, queda en la mayoría de las ocasiones a la interpretación cristiana del docente.

La evolución de los programas educativos desde 1981, muestra que únicamente la sexualidad aparece como un nuevo tema a tratar, mientras que los demás temas se mantienen, con su impronta católica, a lo largo de más de tres décadas.

A partir del estudio de los antecedentes de investigación en esta área, se generó la definición conceptual y operacional de las variables para el estudio. Las variables se determinaron a partir de los principales hallazgos de las 


\section{Cuadro 1. Evolución de los programas de educación religiosa en Costa Rica}

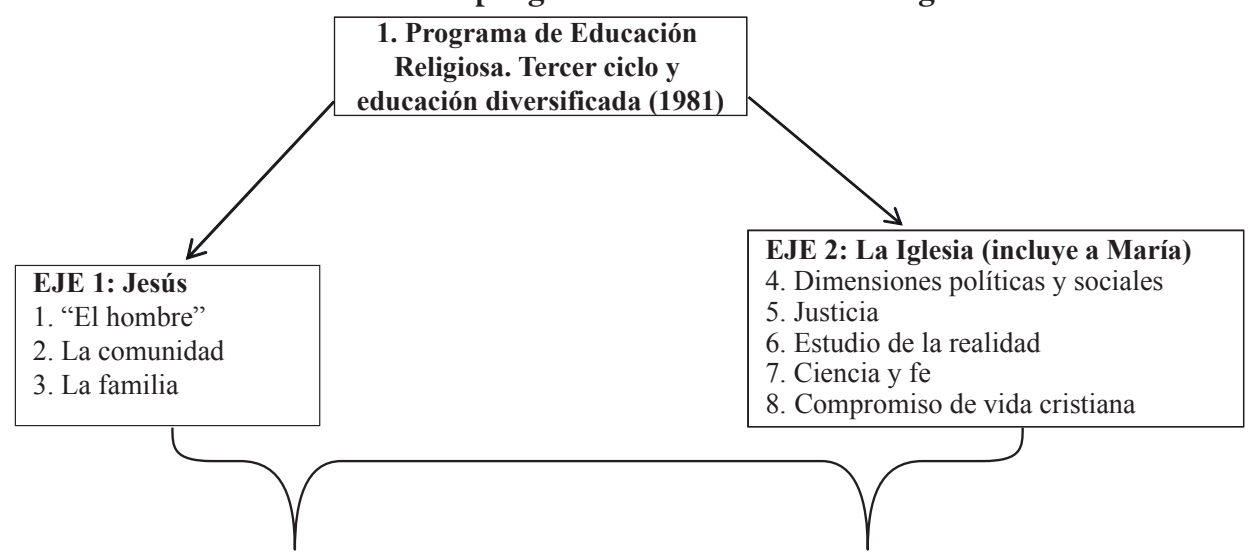

\begin{tabular}{|c|c|}
\hline $\begin{array}{c}\text { 2. Programa de Estudios de la } \\
\text { Educación Religiosa III-IV } \\
\text { Ciclos (1988) }\end{array}$ & $\begin{array}{c}\text { 3. Programa de Estudios: Educación Religiosa: } \\
\text { III Ciclo (1996) y Programas de educación } \\
\text { religiosa educación diversificada y tercer ciclo } \\
\text { (2004) }\end{array}$ \\
\hline
\end{tabular}

\begin{tabular}{|c|c|}
\hline 1. "El hombre" & $\longrightarrow$ 1. Dignidad humana \\
\hline 2. La familia cristiana $\leftarrow$ & $\rightarrow$ 2. Familia y sociedad \\
\hline 3. Fe y sociedad costarricense $\longleftarrow$ & 3. Cultura costarricense \\
\hline 4. Doctrina Social de la Iglesia $\leftarrow$ & $\rightarrow$ 4. Sexualidad (tema transversal) \\
\hline 5. Fe, ciencia y tecnología $\longleftarrow$ & $\rightarrow$ 5. Trabajo (Doctrina Social de la Iglesia) \\
\hline 6. Proyecto de vida cristiano $\leftarrow$ & $\rightarrow$ 6. Ciencia y tecnología \\
\hline 7. Jesús $\longleftarrow$ & $\rightarrow$ 7. Jesús \\
\hline 8. Iglesia $\leftarrow$ & $\rightarrow$ 8. Iglesia (incorpora proyecto de vida cristiano) \\
\hline
\end{tabular}

Fuente: Laura Fuentes Belgrave

investigaciones consultadas, tanto en relación con los contenidos esperados por el estudiantado en esta materia, como con los criterios expresados por el personal docente. Por ello, se propusieron variables que reemplazan los citados ejes organizadores de los programas de educación religiosa tanto en III ciclo como en educación diversificada. Estas variables propuestas responden así a una perspectiva laica en el sentido otorgado a la educación pública por la sentencia de 2010 de la Sala Constitucional ${ }^{1}$, concerniente a la neutralidad religiosa que debería orientar la educación religiosa en Costa Rica.

A partir de los diferentes ejes identificados en los programas educativos mencionados, se elaboró una

1 Sala Constitucional de Costa Rica (2010). Exp: 08-010483-0007-CO, Res. № 2023-2010. Recuperado de: http://sitios.poderjudicial.go.cr/ salaconstitucional/Constitucion \%20Politica/ Sentencias/2010/10-002023.html 
conceptualización que los incorpora, así, en el caso de los temas generadores, se propuso el concepto de derechos humanos, que incluye los ejes de "dignidad humana", "trabajo", "justicia social" y "sexualidad", delimitados para la investigación como sub-variables concretas en las nociones de derecho a la libertad de pensamiento, de conciencia y de religión, derecho al trabajo y derechos reproductivos.

En cuanto al eje de "familia y sociedad" presente en los programas educativos, este se abordó a través del tema generador de estructuras familiares, que implica y promueve una relación de respeto entre las diversas configuraciones familiares. El denominado eje de "cultura costarricense" indicado también en los programas educativos, se amplió a través del tema generador de ética intercultural para la convivencia, que incluye la reflexión sobre el aprendizaje para la convivencia equilibrada en contextos de pluralidad religiosa, a partir de una perspectiva de diálogo interreligioso, que reconoce las espiritualidades ancestrales, así como otros tipos de fe, la increencia y religiones cristianas o no cristianas. En relación con el eje de "ciencia y tecnología", se construyó un tema generador que abarcara cotidianidades educativas vinculadas con el quehacer, los desafíos y las interrogantes que produce este ligamen, a partir del tema generador denominado en este estudio ética ambiental y tecno-científica.
Con respecto a las metas buscadas por la educación religiosa, se identificaron los ejes de "Jesús" e "Iglesia" que incorporan la realización de un proyecto de vida desde la apropiación de contenidos cristianos para su puesta en práctica a través de la evangelización y la práctica personal, apuntando más bien a una meta. Por este motivo, la meta que se sugirió en esta investigación como variable, fue más bien participación comunitaria, en la medida en que implica un compromiso ético con el desarrollo y el bienestar local y personal, a través de una formación para la vida de carácter propositivo, que combata la discriminación en sus distintas vertientes y presente acciones que conduzcan al empoderamiento personal y social.

Por último, se interrogó también el tipo de actividad de comprensión planeada por el cuerpo docente para las clases, a partir de la variable definida como técnicas didácticas, que aunque no se identificó en los ejes localizados en los programas educativos, buscó incorporar como variable, la necesidad de actividades participativas en esta materia (lecturas, exposiciones, trabajos grupales, reflexión grupal en la clase, entre otros), una necesidad señalada por el personal docente y por el estudiantado entrevistado en los distintos estudios revisados para los antecedentes de la investigación. El siguiente cuadro expone la definición de variables sobre la cual se fundamentó la investigación. 


\section{Cuadro 2. Variables utilizadas en la investigación}

\begin{tabular}{|l|}
\hline \multicolumn{1}{|c|}{ Definición conceptual } \\
\hline \multicolumn{1}{|c|}{ Tema generador } \\
1. Derechos humanos \\
Los derechos humanos son aquellos que todo ser humano posee y que tiene \\
el derecho de disfrutar simplemente por su condición de ser humano (...) \\
Se basan en el principio fundamental de que todas las personas poseen una \\
dignidad humana inherente y tienen igual derecho de disfrutarlos, sin importar \\
su sexo, raza, color, idioma, nacionalidad de origen o clase, ni sus creencias \\
religiosas o políticas. (Facio 2003,16)
\end{tabular}

Sub-variables a operativizar:

1.2. Derecho a la libertad de pensamiento, de conciencia y de religión

Artículo 18. Toda persona tiene derecho a la libertad de pensamiento, de conciencia y de religión; este derecho incluye la libertad de cambiar de religión o de creencia, así como la libertad de manifestar su religión o su creencia, individual y colectivamente, tanto en público como en privado, por la enseñanza, la práctica, el culto y la observancia. (Asamblea General de la ONU 1948, 35)

\subsection{Derecho al trabajo (art. 23)}

Artículo 23. 1. Toda persona tiene derecho al trabajo, a la libre elección de su trabajo, a condiciones equitativas y satisfactorias de trabajo y a la protección contra el desempleo. 2. Toda persona tiene derecho, sin discriminación alguna, a igual salario por trabajo igual. 3 . Toda persona que trabaja tiene derecho a una remuneración equitativa y satisfactoria, que se le asegure, así como a su familia, una existencia conforme a la dignidad humana y que será completada, en caso necesario, por cualesquiera otros medios de protección social. 4. Toda persona tiene derecho a fundar sindicatos y a sindicarse para la defensa de sus intereses. (Asamblea General de la ONU 1948, 36)

\subsection{Derechos reproductivos}

7.3. (...) Esos derechos se basan en el reconocimiento del derecho básico de todas las parejas y de cada persona a decidir libre y responsablemente el número de hijos, el espaciamiento de los nacimientos y el intervalo entre éstos y a disponer de la información y de los medios para ello y el derecho a alcanzar el nivel más elevado de salud sexual y reproductiva. También incluye su derecho a adoptar decisiones relativas a la reproducción sin sufrir discriminación, coacciones ni violencia, de conformidad con lo establecido en los documentos de derechos humanos. En el ejercicio de este derecho, las parejas y las personas deben tener en cuenta las necesidades de sus hijos nacidos y futuros y sus obligaciones con la comunidad. La promoción del ejercicio responsable de esos derechos de todos debe ser la base primordial de las políticas y programas estatales y comunitarios en la esfera de la salud reproductiva, incluida la planificación de la familia. Como parte de este compromiso, se debe prestar plena atención, a la promoción de relaciones de respeto mutuo e igualdad entre hombres y mujeres, y particularmente a las necesidades de los adolescentes en materia de enseñanza y de servicios con objeto de que puedan asumir su sexualidad de modo positivo y responsable. (Naciones Unidas 1995, 37-38)

Definición operativa

Tres preguntas administradas mediante cuestionario escrito a muestra de población docente especializada en educación religiosa (una pregunta por cada subvariable) 


\begin{tabular}{|c|c|}
\hline Definición conceptual & Definición operativa \\
\hline $\begin{array}{l}\text { Tema generador } \\
\text { 2. Estructuras familiares } \\
\text { La Convención sobre los derechos del Niño otorga a la familia el carácter } \\
\text { de medio natural y la define como un grupo fundamental de la sociedad } \\
\text { para el crecimiento y el bienestar de todos sus miembros, y en particular } \\
\text { de los niños. Asimismo, aboga por el reconocimiento y la aceptación de las } \\
\text { diversas configuraciones y estructuras familiares asumiéndolas como aptas } \\
\text { y capacitadas para la crianza y constitución de la identidad de los niños. } \\
\text { (UNICEF-UDELAR 2003,9) } \\
\text { Cualquier combinación de dos o más personas unidas por lazos de } \\
\text { consentimiento mutuo, nacimiento y/o adopción/acogida, que, juntas, asumen } \\
\text { responsabilidades para distintas combinaciones de los siguientes aspectos: } \\
\text {-mantenimiento físico y cuidado de los miembros del grupo, -incorporación de } \\
\text { nuevos miembros mediante la procreación o la adopción, -socialización de los } \\
\text { niños, -control social de los miembros, -producción, consumo y distribución de } \\
\text { bienes y servicios; y -formación afectiva. (Vanier Institute of the Family 2015) }\end{array}$ & $\begin{array}{l}\text { Una pregunta administrada } \\
\text { mediante cuestionario } \\
\text { escrito a muestra de } \\
\text { población docente } \\
\text { especializada en educación } \\
\text { religiosa }\end{array}$ \\
\hline $\begin{array}{l}\text { Tema generador } \\
\text { 3. Ética intercultural para la convivencia } \\
\text { La ética intercultural busca: } \\
\text { (...) la contribución, desde las actitudes y la decisión de conductas, a la } \\
\text { convivencia en la diversidad, de manera que se haga posible este requisito tan } \\
\text { esencial a la democracia pluralista. Aunque no tiene únicamente este objetivo } \\
\text { cívico, lo posee también moral, como es ayudar a la supervivencia y prosperidad } \\
\text { humana en condiciones de diversidad étnica, nacional y cultural. Pues la ética } \\
\text { en sí misma pretende un ser humano más feliz, además de quererlo más bueno } \\
\text { y justo. (Bilbeny 2002, 119) } \\
\text { La meta de la con-vivencia no debe confundirse en ningún caso con la } \\
\text { lacificación' de las (conflictivas) controversias entre las diferencias, mediante } \\
\text { la reunión de las mismas en una totalidad superior que se las apropia y armoniza. } \\
\text { Ciertamente quiere la con-vivencia la armonía, sin embargo ésta no debe nacer } \\
\text { por la vía rápida de las apropiaciones reduccionistas, como lo ha intentado } \\
\text { tantas veces la racionalidad occidental. La con-vivencia, al contrario, marca } \\
\text { la armonía que se iría logrando por la constante interacción en el campo } \\
\text { histórico-práctico y por la subsiguiente plataforma intercomunicativa que irían } \\
\text { tejiendo los discursos en la misma explicación de sus controversias. (Fornet- } \\
\text { Betancourt 2001, } 47 \text { ) }\end{array}$ & $\begin{array}{l}\text { Una pregunta administrada } \\
\text { mediante cuestionario } \\
\text { escrito a muestra de } \\
\text { población docente } \\
\text { especializada en educación } \\
\text { religiosa }\end{array}$ \\
\hline
\end{tabular}




\begin{tabular}{|l}
\hline Definición conceptual \\
\hline \multicolumn{1}{|c|}{ Tema generador } \\
4. Ética ambiental y tecno-científica \\
Cuando hablamos de ética ambiental nos referimos a la acción de reflexionar \\
sobre el bien o el mal de nuestros actos en relación con el ambiente. Este \\
ambiente es entendido como el espacio biofísico y social en el cual vivimos. \\
Nuestro espacio de vida y de cultura. No se trata sólo de la naturaleza (plantas \\
y animales) sino que incluye también al ser humano y su actividad cultural \\
(...) se entiende por ética ambiental al proceso reflexivo que se interroga, de \\
forma personal y/o colectiva, sobre lo que son buenas o malas acciones en \\
relación con el ambiente. Se trata pues de una ética en tanto que dinámica \\
de interrogación y de análisis, y no de una ética en el sentido de conjunto de \\
preceptos a seguir (...) La conciencia de la responsabilidad puede permitirnos \\
desarrollar una postura más crítica y autónoma con respecto a las mismas \\
ciencias y tecnología, sus avances, sus métodos, sus impactos, su ideología, sus \\
implicaciones político-sociales, etc. A su vez, esta postura crítica y autónoma \\
puede conducirnos a participar activamente, como fuerza ciudadana, en los \\
debates y toma de decisiones de nuestra sociedad en lo respectivo a los avances, \\
métodos, impactos, ideologías, etc., de las ciencias y la tecnología. (Chávez \\
Tortolero 2004, 486, 487, 488)
\end{tabular}

Meta

\section{Participación comunitaria}

Dinámica de construcción cultural y matriz del poder local articuladas en formas de organización y dirección comunitaria horizontales que potencian una gestión participativa desde la comunicación dialogada en espacios de debate y búsqueda de consenso, en el marco del cual se manifiestan e intercambian emociones, intereses, necesidades, valores, convicciones, saberes, y desarrollan habilidades sociales. Este proceso construye y desconstruye los significados compartidos, los imaginarios e identidades, es decir, los patrones culturales que determinan y son determinados por las especificidades del proceso de participación en cada comunidad. (Hernández 2009, 6-7)

La intervención comunitaria, el desarrollo comunitario y la organización de la comunidad son conceptos que aluden al proceso que ayuda a conseguir el bienestar de la población con la participación social directa y activa de ésta en el diagnóstico, el análisis y la resolución de problemas que le afectan, así como la utilización, el impulso o la creación de sus recursos. (Riera 2005, 76)

\section{Técnicas didácticas}

\section{Actividad de comprensión}

Las técnicas didácticas matizan la práctica docente ya que se encuentran en constante relación con las características personales y habilidades profesionales del docente, sin dejar lado otros elementos como las características del grupo, las condiciones físicas del aula, el contenido a trabajar y el tiempo (...) poseen características propias (...) [son] participativas, tienen un procedimiento a seguir, van hacia un logro de objetivo preciso, desarrollan un proceso colectivo de discusión y reflexión, son aplicables a la imaginación y creatividad, pueden tener múltiples variantes y procedimientos para diferentes objetivos concretos, están al alcance de todos (as) las y los docentes. (Chacón 2010, 5-6)

\author{
Definición operativa \\ Una pregunta administrada \\ mediante cuestionario \\ escrito a muestra de \\ población docente \\ especializada en educación \\ religiosa
}

Una pregunta administrada mediante cuestionario escrito a muestra de población docente especializada en educación religiosa

Una pregunta administrada mediante cuestionario escrito a muestra de población docente especializada en educación religiosa 


\section{El trabajo de campo}

Con el fin de alcanzar el segundo objetivo específico de la investigación; relacionar la práctica pedagógica con el uso de elementos del contexto socio-cultural costarricense, se utilizaron las variables citadas para crear un instrumento cuantitativo, un cuestionario, así como también se definió la población de estudio de toda la investigación.

El tipo de muestra seleccionada para la aplicación de este cuestionario auto-administrado, fue de sujetos voluntarios de la población docente que imparte educación religiosa. Se eligió este tipo de muestra no generalizable, dado que el Ministerio de Educación Pública recolecta los datos de los docentes por centro educativo, por lo que los docentes de educación religiosa que imparten clases en dos colegios o en dos escuelas, aparecen contabilizados dos veces por el Departamento de Estadística de dicho Ministerio, lo cual representa un inconveniente metodológico para la definición del número real de docentes y por lo tanto, para la posibilidad de delimitar una muestra probabilística que sea tanto aleatoria como representativa, al existir un sobre-registro de estos profesionales en los datos estadísticos disponibles. Por este motivo, la técnica utilizada en esta etapa de investigación fue la del sondeo de opinión, al ser imposible definir una muestra representativa cubierta por una encuesta.
La aplicación del cuestionario a los docentes inició el 20 de octubre de 2015 y finalizó el 3 de febrero de 2016, alcanzando 100 cuestionarios respondidos, cuyos datos fueron codificados y procesados para el análisis. En cuanto a las principales características socio-demográficas de esta población, más mujeres (57\%) que hombres (41\%) respondieron al cuestionario, luego, la mayoría de docentes se ubica en un rango de edad entre los $45 \mathrm{y}$ 54 años (31\%), seguidos del segmento etario entre 25 y 34 años (28\%), a continuación se encuentra el grupo entre 35 y 44 años con un $22 \%$, el sector entre 21 y 24 años con un $12 \%$, y el grupo de 55 años y más con un $9 \%$.

La mayoría de los docentes trabaja en I y II ciclo (53\%), así como en III ciclo y educación diversificada (28\%), también, se contó con representatividad de entre un $1 \%$ y un $6 \%$, de las Direcciones Regionales Educativas de Puntarenas, Grande de Térraba, Turrialba, San José Central, Puriscal, San José Oeste, Heredia, Desamparados, San Carlos, Aguirre, Limón, Guápiles, San José Norte, Pérez Zeledón, Los Santos, Cartago, Occidente, y un $40 \%$ de Alajuela. De esta población docente, un $47 \%$ enseña solamente en un centro público, pero de ahí en adelante hay diversas combinaciones posibles, donde destaca un $14 \%$ que trabaja en tres centros públicos al mismo tiempo o incluso un $10 \%$ que 
trabaja en dos centros públicos, lo cual demuestra la falseabilidad de los datos del Departamento de Estadística del MEP con respecto al número total de esta población.

Por otra parte, la segunda fase de la investigación, de tipo cualitativo, se desarrolló del 4 de abril al 21 de junio de 2016, y buscó responder al tercer objetivo del estudio: conocer las percepciones y expectativas del estudiantado sobre los contenidos y la estrategia pedagógica de la asignatura religión, esto se hizo mediante la transformación de las variables y los ítems del cuestionario aplicado en la etapa cuantitativa, en temas y categorías para realizar diez grupos focales, con estudiantes de III ciclo y de educación diversificada de colegios públicos. Se seleccionó esta muestra estudiantil, puesto que los jóvenes en este grupo etario han recorrido toda la ruta escolar, lo cual implica el conocimiento de la currícula religiosa desde la primaria hasta el final de la educación secundaria, un hecho que confiere un valor comunicacional relevante a su experiencia. En el siguiente cuadro se observan algunos de los principales datos arrojados por los grupos focales.

\section{Cuadro 3. Colegios participantes en los grupos focales}

\begin{tabular}{|c|c|c|c|c|}
\hline Zona & Colegios públicos & $\begin{array}{c}\text { Provincias } \\
\text { costarricenses }\end{array}$ & $\begin{array}{l}\text { Fecha de } \\
\text { realización }\end{array}$ & $\begin{array}{c}\text { Número de } \\
\text { participantes } \\
\text { por grupo focal }\end{array}$ \\
\hline \multirow[t]{6}{*}{ RURAL } & 1. Colegio de Candelaria de Naranjo & Alajuela & $21 / 04 / 16$ & 16 \\
\hline & $\begin{array}{l}\text { 2. Colegio Norma Steinvorth } \\
\text { (San José de la Montaña) }\end{array}$ & Heredia & $04 / 04 / 16$ & 16 \\
\hline & 3. Liceo de Picagres de Mora & San José & $10 / 05 / 16$ & 14 \\
\hline & 4. Colegio Técnico Profesional de Batán & Limón & $31 / 05 / 16$ & 22 \\
\hline & $\begin{array}{l}\text { 5. Colegio Innovación Académica de } \\
\text { Matina }\end{array}$ & Limón & $21 / 06 / 16$ & 18 \\
\hline & & & & Total: 86 \\
\hline \multirow[t]{6}{*}{ URBANA } & 1. Instituto de Alajuela & Alajuela & $12 / 04 / 16$ & 5 \\
\hline & 2. Conservatorio Castella & Heredia & $05 / 04 / 16$ & 25 \\
\hline & 3. Liceo de Heredia & Heredia & $22 / 04 / 16$ & 22 \\
\hline & $\begin{array}{l}\text { 4. Unidad Pedagógica Colegio República } \\
\text { de México }\end{array}$ & San José & $17 / 05 / 16$ & 15 \\
\hline & 5. Liceo Luis Dobles Segreda & San José & $27 / 05 / 16$ & 27 \\
\hline & & & & Total: 94 \\
\hline
\end{tabular}

Fuente: Laura Fuentes Belgrave 
En total, participaron 180 estudiantes, con un promedio de edad de 16 años, de los cuales 96 fueron mujeres y 84 hombres. La mayoría de estudiantes se identificaron como personas católicas, seguidas de personas cristianas evangélicas y personas sin religión, así como otras afiliaciones diversas.

\section{Los hallazgos de la investigación}

Este estudio buscó analizar las diferencias y las semejanzas entre la práctica docente y la percepción estudiantil alrededor de la educación religiosa, comparando los resultados obtenidos en las dos fases de investigación. De forma general, los resultados muestran apreciaciones contradictorias sobre el quehacer de los docentes. Estos últimos aseguran de forma mayoritaria en el sondeo, que realizan una labor congruente con los principios pedagógicos que promueve el Ministerio de Educación Pública, -a pesar de que esta institución haya oficializado programas educativos de innegable fondo cristiano-, mientras que los estudiantes cuestionan ampliamente estas prácticas educativas $y$, por ende, las respuestas de los profesores en lo concerniente a su ocupación.

El primer gráfico muestra que un $45 \%$ de docentes considera que el derecho a la libertad de pensamiento, de conciencia y de religión implica llevar la palabra de Dios a todas las personas, seguido por un $42 \%$ que piensa que este derecho incluye conservar o cambiar su religión o no profesar ninguna creencia y manifestarlo en público o en privado. Estas apreciaciones, se reflejan en las experiencias estudiantiles relatadas en los grupos focales. Como se observa en este testimonio: "El pastor también me daba
Gráfico 1. ¿Cuál opción incluye el derecho a la libertad de pensamiento, de conciencia y de religión?
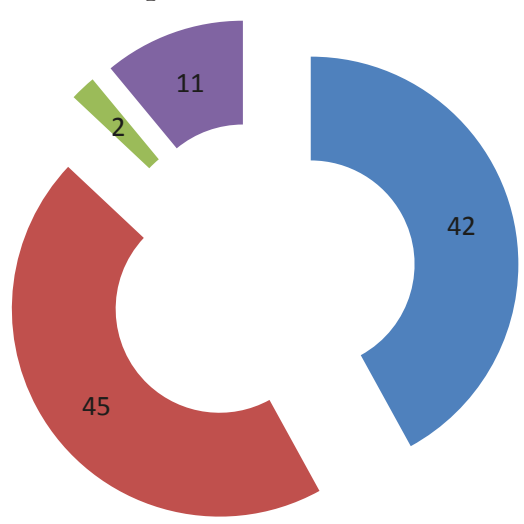

- Conservar o cambiar su religión o no profesar ninguna creencia y manifestarlo en público o en privado

- Llevar la Palabra de Dios a todas las personas

Prohibir cualquier tipo de expresión anti-religiosa

No sabe/No responde un material sólo para mí, pero la escuela estaba a la par de una iglesia y nos sacaban en horas lectivas y nos llevaban a misa" (Grupo focal realizado en Colegio Norma Steinvorth, San José de la Montaña, Heredia, 04/04/16).

Fuente: Laura Fuentes Belgrave 
Los estudiantes entrevistados en los grupos focales narran con franqueza experiencias vividas que demuestran el irrespeto a la libertad de conciencia, de pensamiento y de religión, que experimentan principalmente los no católicos. A diferencia de otras categorías analizadas en esta investigación, en este punto, sí coinciden las respuestas de docentes y colegiales, que ilustran cómo se lesiona el derecho a esta libertad, mediante una imposición evangelizadora.

Si bien, la perspectiva de derechos humanos tiende a sobresalir en las respuestas de los docentes en relación con su labor vinculada con la dignidad humana ligada al derecho al trabajo, con el abordaje de los derechos reproductivos, las estructuras familiares y la ética intercultural para la convivencia,-tal como se aprecia en los gráficos posteriores-, la réplica de los estudiantes sobre estos temas generadores afronta con creces esta visión, al relatar la forma en que sus clases de educación religiosa encarnan el reverso de las respuestas dadas por sus profesores, cuyas prácticas estarían mayoritariamente determinadas, según el alumnado, por imperativos dogmáticos que excluyen otras visiones de mundo que no respondan al patrón católico, o a veces cristiano, de mayor tradicionalidad, como bien se señala en este testimonio: "A mí más que todo, no me gustaría hablar de religiones, de que si es evangélica o es católica o si es ateo, más que todo, me gustaría hablar como de la vida" (Grupo focal realizado en Liceo de Picagres de Mora, San José, 10/05/16).

\section{Gráfico 2. ¿Cómo puede el trabajo contribuir a la dignidad humana?}

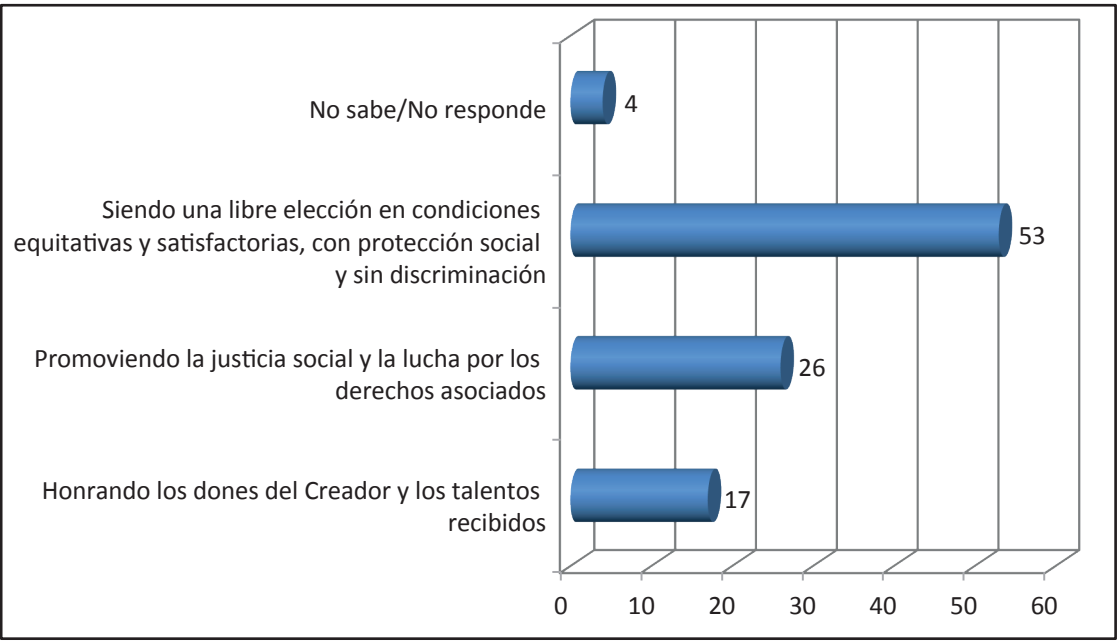

Fuente: Laura Fuentes Belgrave 
En la relación entre trabajo y dignidad humana, un 53\% de docentes se inclina por considerar que el trabajo contribuye a la dignidad humana siendo una libre elección en condiciones equitativas y satisfactorias, con protección social y sin discriminación. Para las personas estudiantes, la formación en valores como solidaridad, amor e igualdad, parece apuntar al fomento de la dignidad humana, aún si según los estudiantes se constriñe más el tema a cuestiones atingentes a la virginidad o a la abstinencia sexual que a situaciones más complejas, relacionadas con sus vidas afectivas, laborales y familiares.

En el caso concreto de la posibilidad de abordar la sexualidad como un eje transversal de la educación religiosa, en el cuerpo docente se impone la economía del miedo, que por una parte promueve rechazo hacia el derecho a la salud sexual y reproductiva, aunque afirme lo contrario en sus respuestas al cuestionario, con una contundente mayoría de 54\% que afirma que colaboraría con la toma de decisiones responsables e informadas relativas a la salud sexual y reproductiva, de incluirse la sexualidad como un eje transversal en la educación religiosa.

La profesora nos decía que la mujer no tiene que ser "picaflor", sólo juntarse con otras amiguitas. Decía que las mujeres siempre tienen que jugar con barbies. Y teníamos una compañera que no le gustaba y la profesora decía que eso estaba mal, que ella era lesbiana y se iba a condenar. (Grupo focal realizado en Colegio Norma Steinvorth, San José de la Montaña, Heredia, 04/04/16)

En las clases, contrariamente a las respuestas de los docentes, los alumnos revelan que sus tutores promueven la ignorancia del estudiantado o la implantación de los dictados católicos como registros de verdad incuestionable. No obstante, los estudiantes demuestran apertura e interés ante el planteamiento de temáticas de esta magnitud, pese al nada desdeñable $40 \%$ de docentes, que buscaría reforzar la moral y el aprendizaje de los valores cristianos si incluyera la sexualidad en sus clases.

Es preciso también señalar que existe una coincidencia de opiniones sobre la mayoría de las variables evaluadas en el sondeo, entre los docentes más jóvenes (21 a 24 años) y los de mayor edad (55 años y más). Esta sincronía entre los sectores etarios mencionados, tiende a acrecentarse en la conjunción de contenidos relacionados con derechos sexuales y reproductivos, exhibiendo rechazo y conservadurismo hacia los intereses estudiantiles.

Yo siento que una familia no solo se limita a papá-mamá, hijo e hija; una familia es mucho más amplia, hay amigos que son más familia que la de sangre, y pensamos que personas de un mismo sexo pueden conformar una familia porque son 
Gráfico 3. ¿Qué implica incluir la sexualidad como un eje transversal en la educación religiosa?

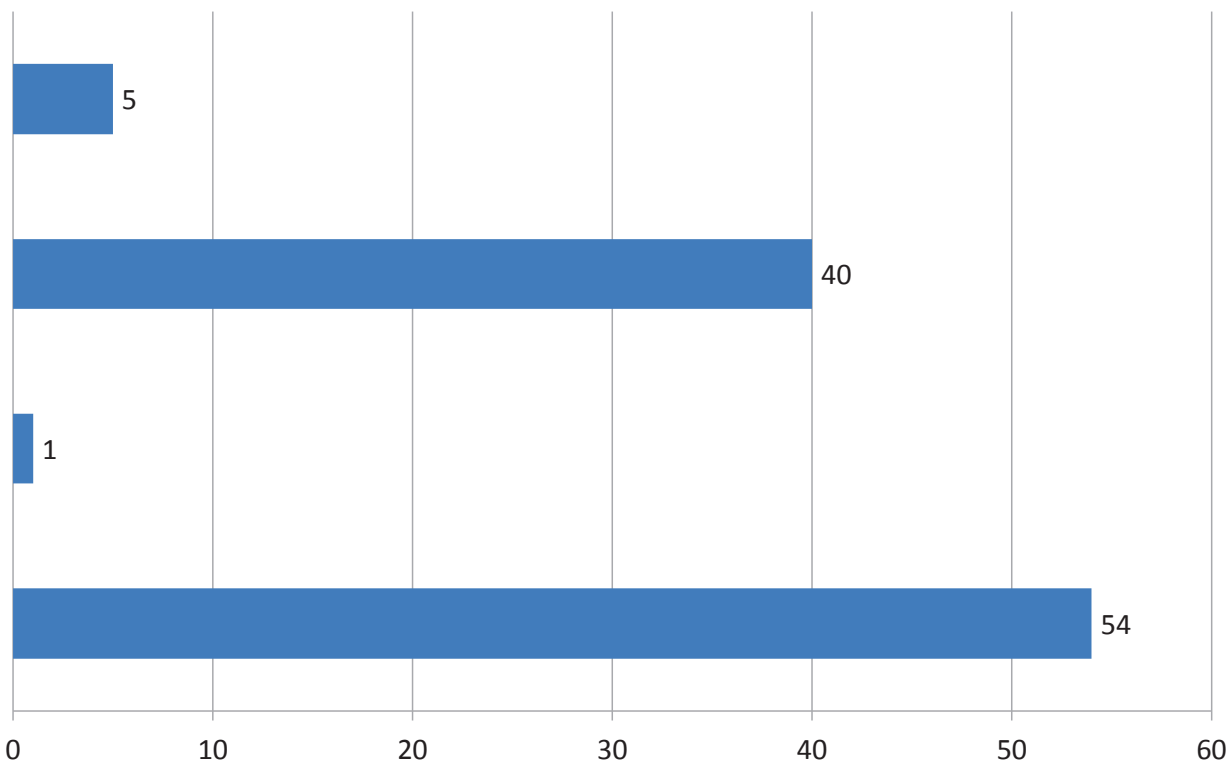

Fuente: Laura Fuentes Belgrave

personas igualmente llenas de amor por dar, son personas más comprensivas, son personas que por el rechazo se encargan de darle a sus hijos amor, comprensión, sabiendo cómo tratar y respetar a las personas, de hecho, creo que hasta más que nosotros mismos que somos heterosexuales. Por eso yo apoyo y creo que las parejas del mismo sexo puedan tener hijos. Para la sociedad y la religión eso está mal, pero para mí no está mal, creo que un homosexual puede darle mucho amor a un hijo. (Grupo focal realizado en Colegio Innovación Académica de Matina, Limón, 21/06/16)
En la composición de las estructuras familiares, los estudiantes también se rebelan contra los contenidos impartidos, marcados en la práctica, por la hostilidad de los docentes hacia formas de familia no heterosexuales, mientras que los estudiantes se inclinan por la necesidad de promover el amor como el valor fundamental que debe imperar en las familias, independientemente de si existen lazos de consanguinidad entre sus miembros o si están conformadas por personas sexualmente diversas. 


\section{Gráfico 4. ¿Cuáles de estas ideas busca transmitir a los estudiantes sobre sus familias?}

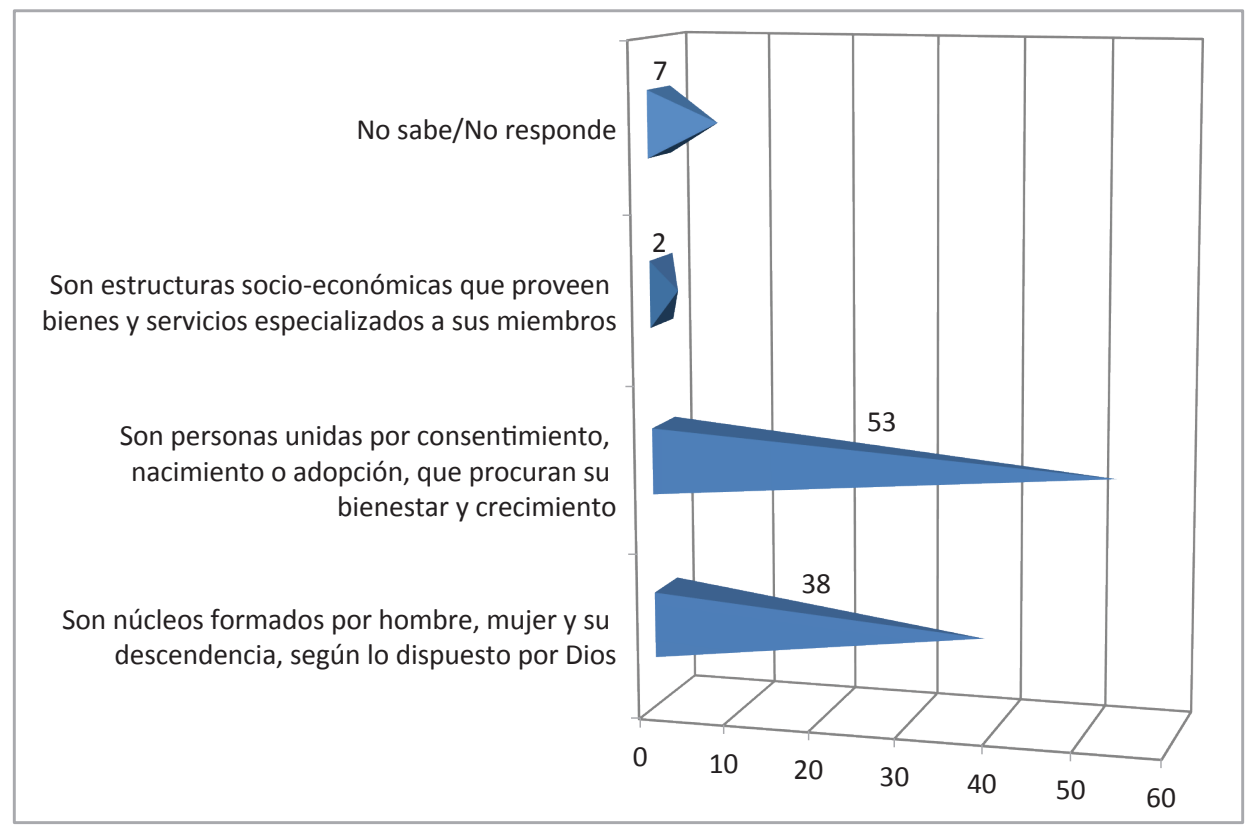

Fuente: Laura Fuentes Belgrave

En el sondeo, un $53 \%$ de docentes asevera que las familias serían personas unidas por consentimiento, nacimiento o adopción, que procuran su bienestar y crecimiento, a contrapelo de lo que predican en sus clases. Hay que notar que solamente un $38 \%$ afirma que serían núcleos formados por hombre, mujer y su descendencia, según lo dispuesto por Dios, una respuesta más conforme a lo narrado por los estudiantes.

En relación a los aspectos evaluados en torno a la ética intercultural para la convivencia, en las respuestas de los docentes predomina un tono políticamente correcto, que si bien se mantiene de forma general en el cuestionario, resalta específicamente en lo que concierne al reconocimiento de la pluralidad étnica y cultural, el fomento al diálogo entre diversas confesiones religiosas y la interacción respetuosa entre creyentes y no creyentes, que alcanzan porcentajes superiores al 90\% de aplicación en toda la muestra de docentes que participó en el sondeo, como se observa en los próximos gráficos. 
Gráfico 5. Reconocimiento de la pluralidad étnica y cultural

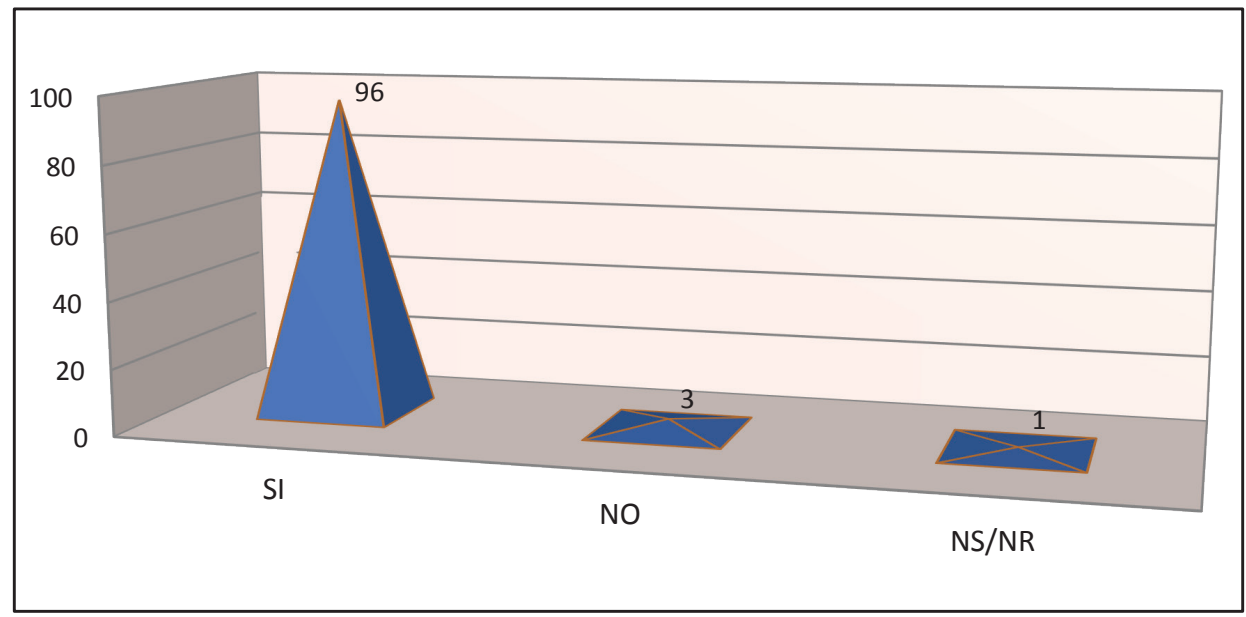

Fuente: Laura Fuentes Belgrave

Gráfico 6. Fomento al diálogo entre diversas confesiones religiosas

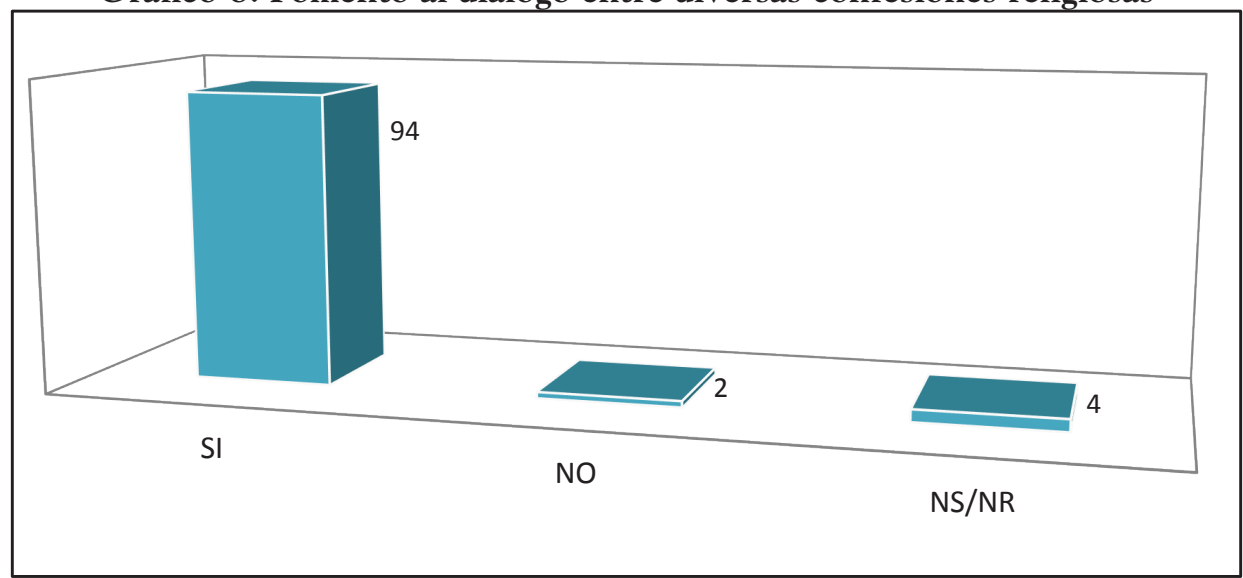

Fuente: Laura Fuentes Belgrave 
Gráfico 7. Interacción respetuosa entre creyentes y no creyentes

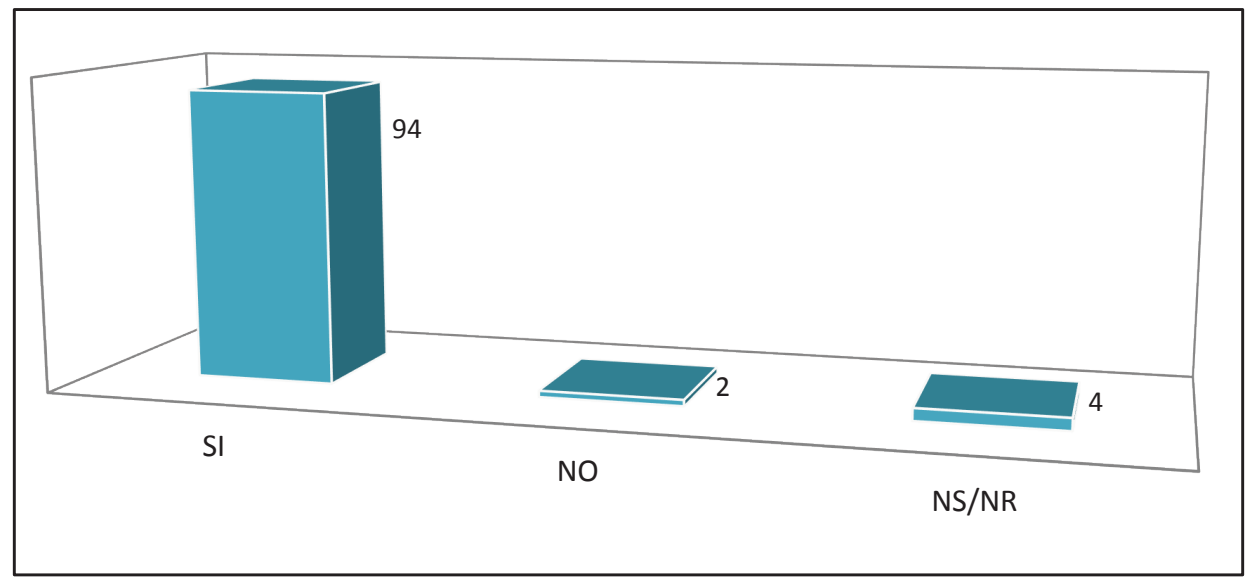

Fuente: Laura Fuentes Belgrave

El profesorado brinda en relación con los asuntos expuestos en los gráficos precedentes, las respuestas esperadas y satisfactorias, que implican que mayoritariamente incluye los contenidos mencionados como temas generadores en las clases de educación religiosa. No obstante, la mayoría estudiantil confiesa que no solamente nunca ha tenido ninguna aproximación a estos temas, sino que además le despertaría un profundo interés la posibilidad real de conocer la historia y las narrativas sagradas de otras religiones y espiritualidades, al formar incluso, parte de familias interconviccionales.

Mi mamá es católica, mi papá es adventista, mi hermano, mi hermana y yo, somos cristianos, yo escogí lo que quería ser y todos nos llevamos bien. En el colegio donde yo estaba en $\mathrm{Ni}$ caragua, no recibía religión. Yo casi no he venido a esta clase en Costa Rica, pero ahora quiero presentar una carta para no recibir religión. A veces los fines de semana voy con $\mathrm{mi}$ hermano al culto, pero es que esta clase no se relaciona mucho con la religión cristiana, sólo con el catolicismo. (Grupo focal realizado en el Instituto de Alajuela, Alajuela, 12/04/16)

Por otra parte, según los estudiantes, el diálogo entre creyentes y no creyentes presenta conflicto en las clases, tanto para docentes como para alumnos. Como se observa en este testimonio: "El problema es que siempre se habla de la existencia de Dios y no de la religión. Por eso nunca pueden hablar las personas ateas" (Grupo focal realizado en Colegio Conservatorio Castella, Barreal de Heredia, 05/04/16). 
Pese a que el profesorado afirma mayoritariamente que promueve interacciones entre creyente y no creyentes, los colegiales aseveran que el intercambio es ficticio y las condiciones para ello aún no existen, al estar la educación religiosa todavía colmada de prenociones sobre las personas sin religión, ateas y agnósticas; ideas compartidas tanto por profesores como por los adolescentes.

Por otra parte, como plantea el gráfico anterior, la exploración de espiritualidades indígenas y afrodescendientes, que implica un accionar pedagógico contundente, ligado al territorio costarricense y sus raíces e influencias culturales, cuenta con menos docentes que la apliquen. Solamente un $57 \%$ de profesores realiza una acción educativa en este sentido, pese a que también se encuentran otros comportamientos pedagógicos, capaces de entablar diálogos con tradiciones religiosas locales y foráneas, pero según los estudiantes aún son minoritarios:

Acerca de espiritualidades indígenas y afrodescendientes no hemos aprendido nada, todo ha tenido que ver con el cristianismo, no es molesto, yo creo en Dios, pero es que tampoco hay que encerrarse y volverse ignorante de las otras religiones, porque lo que hacen muchos cristianos es criticar sin saber qué es, o en qué creen los demás. Sí nos interesaría ver contenido relacionado con la pluralidad étnica y cultural en Costa Rica, siento que es algo que se debería de ver, sería necesario para ayudar con la tolerancia, el respeto y la igualdad. (Grupo focal realizado en Liceo Luis Dobles Segreda, San José, 27/05/16)

\section{Gráfico 8. Exploración de espiritualidades indígenas y afrodescendientes}

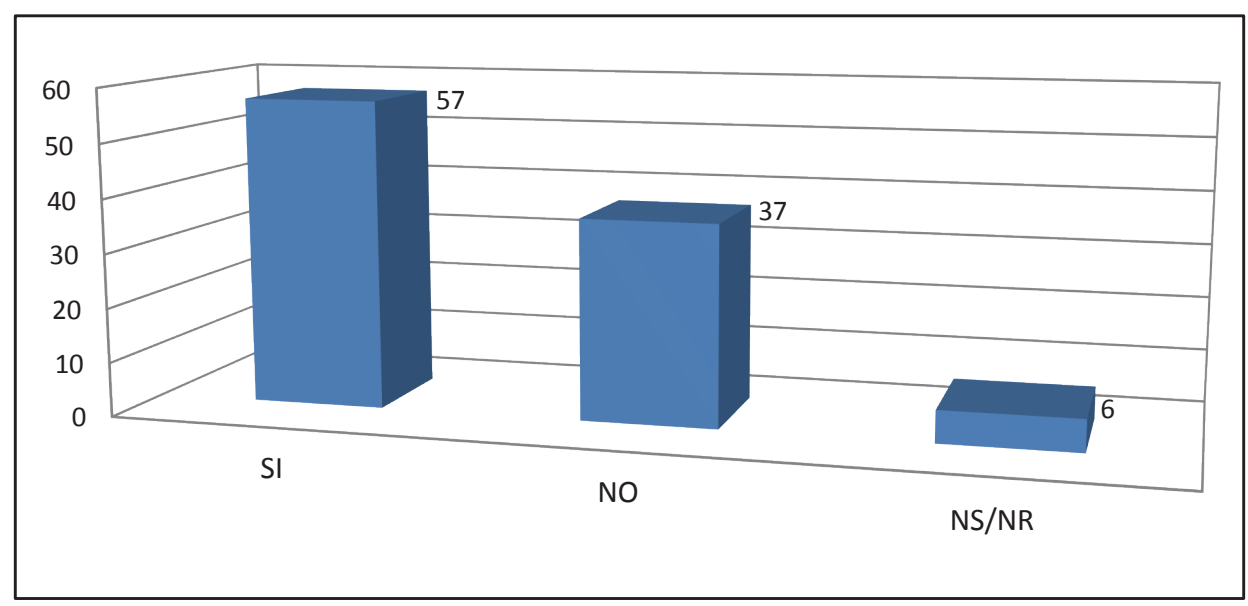

Fuente: Laura Fuentes Belgrave 
Si bien, en Costa Rica la educación religiosa no se supone que sea confesional en términos católicos, en razón de la resolución № 2023-2010 de la Sala Constitucional que declara su neutralidad, en la práctica no funciona de esta forma, eludiendo las expectativas espirituales y de conocimiento en esta materia, que presentan de forma creciente los estudiantes, a quienes se les imparte en muchos casos, un tipo de catequesis ajena tanto a sus creencias e itinerarios espirituales, como a su derecho a una educación laica.

El nudo de la problemática que impide avanzar hacia una educación religiosa inclusiva y respetuosa de las alteridades no católicas, lo constituye el énfasis que mayoritariamente continúa poniendo el cuerpo docente en la enseñanza de una moral de concepción cristiana. Como se expresa en el siguiente comentario: "Menos Biblia y religión no se puede dar, de hecho los profesores le llaman falta de moral. Nos habían dejado una tarea de que buscáramos no sé qué en la Biblia, y bueno, yo me negué a hacerla" (Grupo focal realizado en Liceo de Heredia, Heredia, 22/04/16).

A pesar de las expectativas estudiantiles, como se observa en el gráfico anterior, un $65 \%$ de los docentes afirma la moral cristiana, y los estudiantes corroboran que en sus clases se les imparte la idea de Dios y la interpretación de la doctrina católica desde una visión prohibitiva y sacrificial, lo cual fustiga las vidas de las personas jóvenes, dado que se ignoran las situaciones de violencia en sus múltiples ramificaciones, que vive la

\section{Gráfico 9. Afirmación de la moral cristiana}

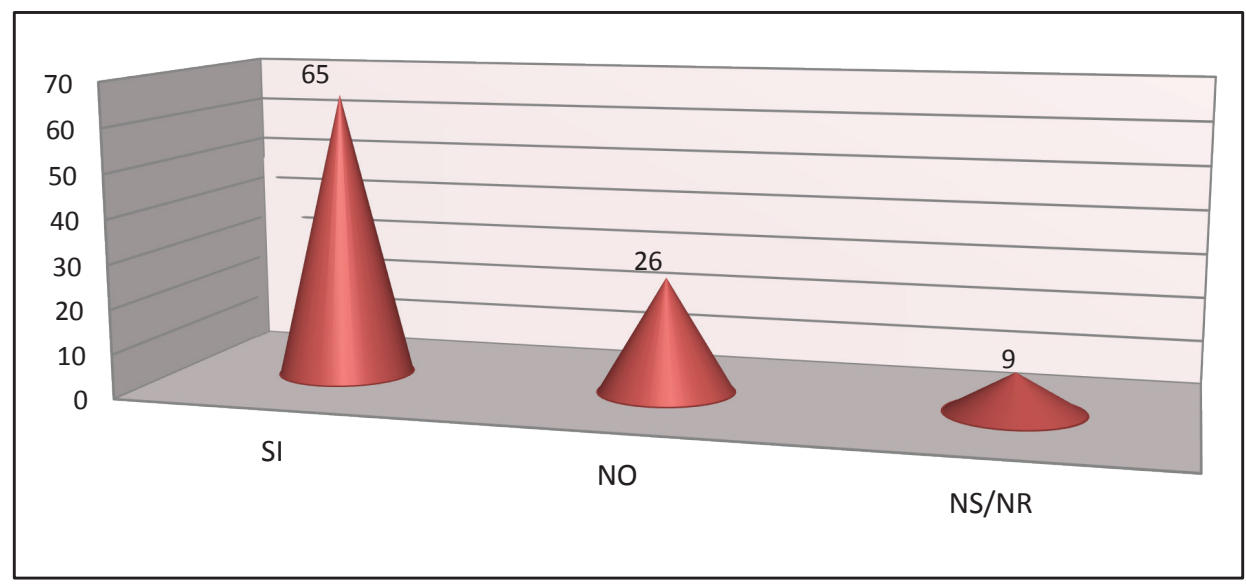

Fuente: Laura Fuentes Belgrave 


\section{Gráfico 10. Aplicación literal de lecturas bíblicas}

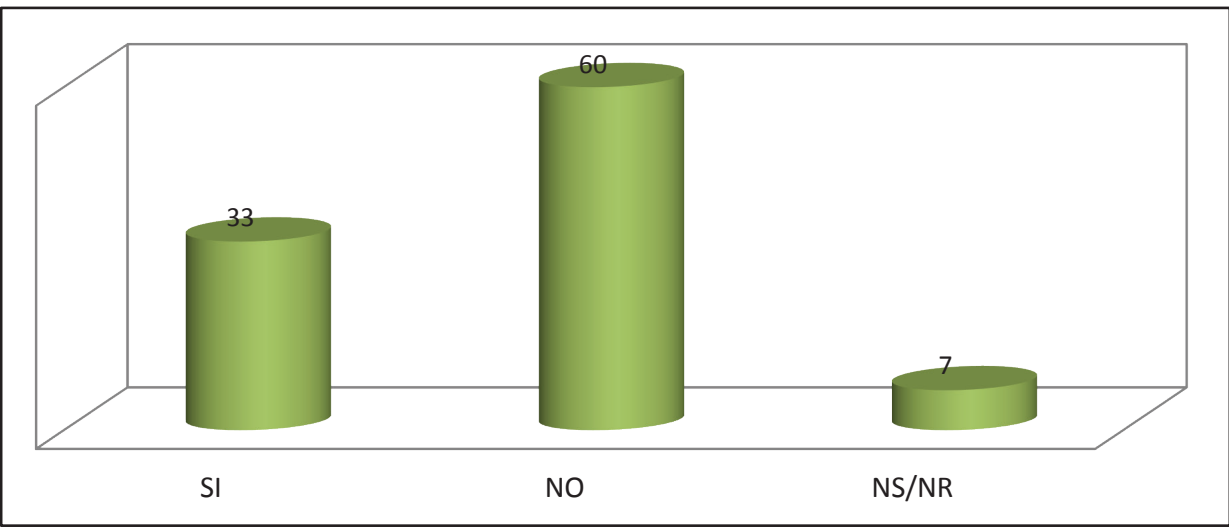

Fuente: Laura Fuentes Belgrave

juventud en su adolescencia y entornos familiares y geográficos.

Un tipo de lectura bíblica contextualizada, podría responder parcialmente a estas situaciones apremiantes vividas por los adolescentes, aún si se prescindiera de contemplar otras creencias en las clases de educación religiosa, pero aunque los docentes encuestados rechacen el hecho de aplicar la literalidad bíblica, con un $60 \%$ que así lo asevera, los colegiales expresan testimonios que ponen en entredicho a sus tutores:

En cuanto a la aplicación literal de la Biblia pensamos que a la hora de aplicarla en la vida cotidiana debe hacerse más práctico, porque hay pensamientos o formas de actuar que pueden ir en contra de la dignidad humana. (Grupo focal realizado en Liceo Luis Dobles Segreda, San José, 27/05/16)
Para el estudiantado no solamente se abusa de la literalidad bíblica, sino que no se realiza la necesaria contextualización histórico-cultural de las condiciones en que fue escrito el texto, el cual no se explica en virtud de las figuras literarias que utiliza, ni tampoco es adaptado a las circunstancias actuales, prácticas de literalidad bíblica que solo serían admitidas por el 33\% de la muestra de docentes, tal como lo muestra el siguiente gráfico.

Es relevante destacar que las diferencias porcentuales entre las respuestas de mujeres y hombres no tienden a ser significativas en el estudio, y por ello no se han mostrado gráficos vinculados a ello, aunque sí es necesario aclarar que las mujeres muestran posiciones levemente más tradicionales. Por pocos puntos porcentuales, ellas se muestran más inclinadas a reforzar los valores 
cristianos y a llevar la Palabra de Dios a los estudiantes, un aspecto en el que también convergen los docentes ubicados en el rango de edad entre 25 y 34 años, especialmente en lo que atañe al reforzamiento de la moral cristiana, por otro lado, la evangelización es liderada por el sector etario entre 35 y 44 años. No obstante, las mujeres son menos propensas que los hombres a aplicar la literalidad bíblica en sus clases, aunque paradójicamente, sean estos últimos quienes dicen incentivar más la crítica.

En cuanto a la ética ambiental y tecno-científica como tema generador en las clases de educación religiosa, la percepción estudiantil es que su desarrollo es prácticamente nulo, pese a que los docentes se inclinan mayoritariamente en sus respuestas, por concientizar a sus estudiantes sobre el uso responsable de los recursos naturales, con un $42 \%$, lo cual denota una posición anacrónica en el tratamiento de estos contenidos, seguido de un 38\%, cuyo énfasis estaría en la interrogación y análisis sobre estos temas.

En las pocas ocasiones que el tema ha sido visto en clase, según el estudiantado, su tratamiento se caracteriza más por presentar relaciones conflictivas entre ciencia y religión.

Reflexionamos como que la ciencia había sido creada para negar la existencia de Dios. Yo no estoy de acuerdo,

\section{Gráfico 11. ¿Cómo desarrolla la reflexión ética sobre ambiente, ciencia y tecnología en su clase?}

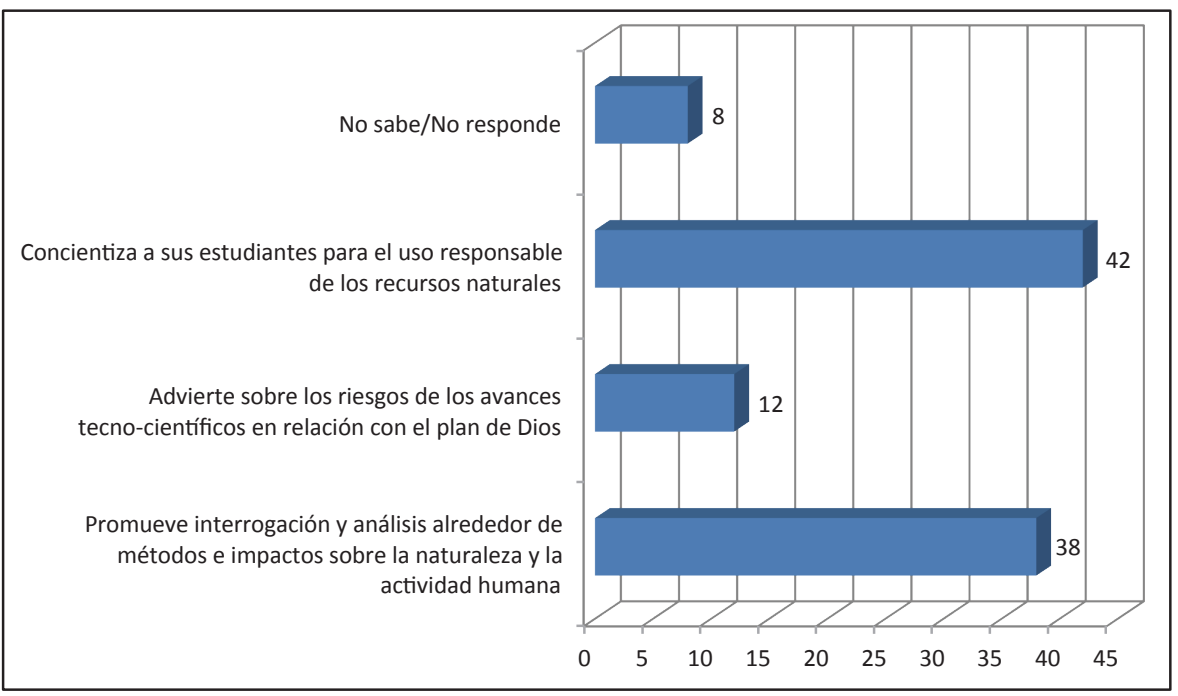

Fuente: Laura Fuentes Belgrave 
hay ciertas cosas que tienen explicación, pero lo que va para la ciencia y lo que va para la fe, es diferente. (Grupo focal realizado en el Instituto de Alajuela, Alajuela, 12/04/16)

Esta perspectiva docente ni siquiera toma en cuenta la evolución que ha tenido el Vaticano sobre dichos asuntos en los últimos cincuenta años, considerando que la mayoría de los docentes ofrece una formación en esta materia orientada por principios católicos. Sin embargo, las personas jóvenes parecen deseosas de abordar la ética ambiental y tecno-científica en relación directa con sus inquietudes sobre el devenir de la humanidad.

También se examinó como posible meta para la realización del proyecto de vida de los estudiantes, el fomento a la participación comunitaria desde la educación religiosa. Como se indica en este testimonio, recogido en el Colegio Conservatorio Castella: "Sólo se cantaba "Dios está aquî" o se coloreaba, ¿cómo iba a haber una organización para la sociedad civil?" (Grupo focal realizado en Colegio Conservatorio Castella, Barreal de Heredia, 05/04/16).

Según el alumnado, esta área se encuentra en franco descuido por parte de los docentes, pese a los porcentajes nacionales que muestran la necesidad de promover la organización de las personas jóvenes ante los ambientes de riesgo que tienden a desempoderarlos.

Gráfico 12. ¿Qué incentiva en sus estudiantes para la realización de su proyecto de vida en la sociedad?

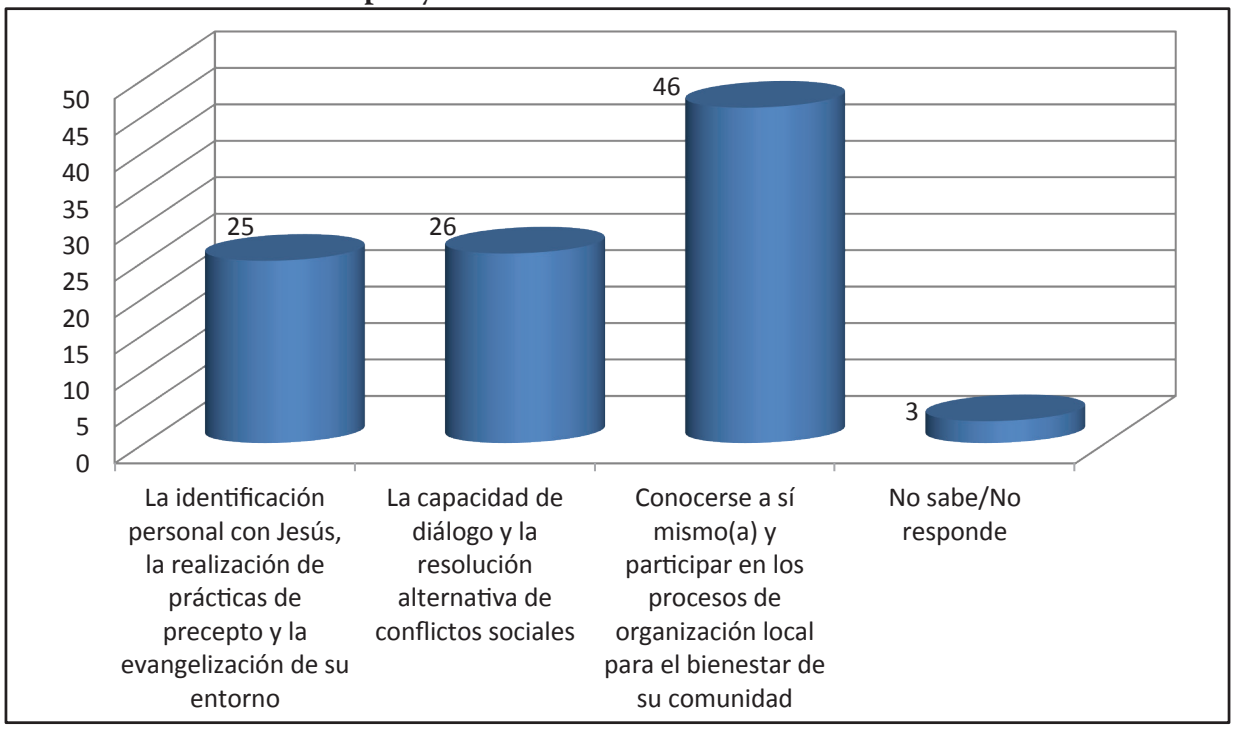

Fuente: Laura Feuntes Belgrave 
En este rubro, evaluado en el gráfico previo se encontró que, si bien el profesorado afirma incentivar la participación comunitaria con un $46 \%$, la evangelización de los estudiantes también es promovida en un buen grado por un $25 \%$ de los docentes, así como un $26 \%$ promueve la capacidad de diálogo y la resolución alternativa de conflictos sociales.

Por otra parte, la aplicación y tipo de actividades de comprensión utilizadas en el aula, concebidas como técnicas didácticas, y sugeridas por Chacón (2010), como dinámicas vivenciales (las de animación y las de análisis), técnicas de actuación, técnicas auditivas y audiovisuales, y técnicas visuales (técnicas escritas y técnicas gráficas), constituyen un aspecto donde también se comprueba la brecha entre las prácticas del profesorado y las percepciones de las personas estudiantes.

Para los estudiantes no se incentiva el pensamiento crítico ni la participación en clase, contrariamente a lo afirmado por los docentes, de los cuales $48 \%$ dice propiciar un proceso colectivo de discusión y reflexión que potencie la imaginación y la crítica, seguido de un $32 \%$ que motiva a lecturas, exposiciones y trabajos grupales

\section{Gráfico 13. ¿Cuál es el enfoque que considera más importante para aplicar}
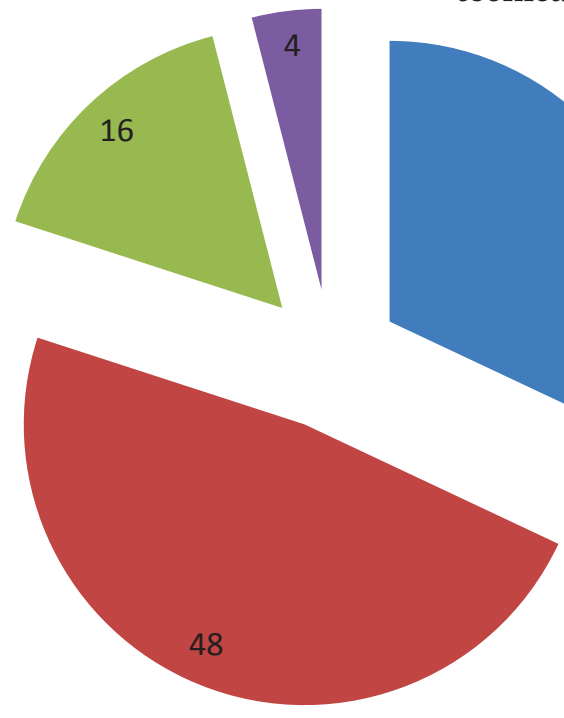

Motivar a lecturas, exposiciones y trabajos grupales que fortalezcan los valores cristianos

32

- Propiciar un proceso colectivo de discusión y reflexión que potencie la imaginación y la crítica

Realizar actividades participativas que sigan disciplinadamente los contenidos del programa educativo

No sabe/No responde

Fuente: Laura Fuentes Belgrave 
que fortalezcan los valores cristianos. Como se lee a continuación:

El profe llegaba y ponía un reproductor frente a la pizarra y empezaba a dar diapositivas, y honestamente, en la forma que él explicaba no era como muy entretenida, entonces lo que hacía más bien era aburrirnos, yo honestamente me aburría y me acostaba a dormir, yo me sentaba en la esquina a dormir, para qué mentir. Diay, ahora nos ponen videos a veces motivacionales y abordamos el tema y así opinamos. (Grupo focal realizado en Colegio de Candelaria de Naranjo, Alajuela, 21/04/16)

Según los estudiantes, existen transformaciones en curso, relacionadas con el interés de algunos docentes en promover las discusiones en clase, aunque este tipo de dinámica todavía es de escala reducida, pues la mayoría de profesores continúa solicitando víveres a sus estudiantes con el fin de hacerlos aprobar la materia, poniendo en práctica una metodología poco pedagógica.

\section{Conclusiones}

En suma, es posible afirmar que existe una minoría de docentes -los agentes que recién ingresan al campo escolar-, cuyas prácticas en la educación religiosa están renovándose, en comunicación con los intereses y las demandas estudiantiles, contextualizados en un cuadro de transformaciones socio-culturales de la sociedad costarricense. Esta minoría podría subvertir el habitus (Bourdieu, 1990) o el esquema de prácticas y percepciones ligadas a la educación religiosa, pero el sistema de fuerzas imperante en el campo les es desfavorable, pues no son los estudiantes quienes les legitiman, sino las autoridades institucionales, cuyos programas educativos ofrecen reconocimiento a los agentes dominantes en el campo escolar. Estos últimos son la mayoría de docentes, los agentes con mayor capital simbólico acumulado, quienes reproducen el habitus del campo escolar tradicionalmente atribuido a la educación religiosa y continúan adoctrinando a sus estudiantes, desde una visión catequística que no solo ignora la complejidad de la convivencia intercultural e interreligiosa, sino que también reproduce discriminación hacia distintos sectores sociales.

Los educandos que participaron en los grupos focales caracterizan las prácticas de los docentes por su fomento a la discriminación hacia creencias no cristianas y a la increencia, así como a identidades, expresiones $\mathrm{u}$ orientaciones sexuales y de género no heterosexuales. Según el estudiantado, estas prácticas también se singularizan por su imposición doctrinaria y su indiferencia a metodologías críticas y participativas para el trabajo en clase. 
Desde este punto de vista, la necesidad de un tema generador que ahonde en las relaciones interculturales e interreligiosas para promover una ética de la convivencia que fomente el reconocimiento de los otros, el encuentro y el vínculo entre distintas identidades, constituye una prioridad para la educación religiosa en Costa Rica, pues la población dentro del sistema educativo aún no tiene las herramientas ni para formar, ni para aprehender, bajo estas coordenadas que entraña la globalización en contextos locales.

\section{Bibliografía}

Asamblea General de la ONU. 1948. Artículo 18. Declaración Universal de Derechos Humanos. Nueva York: Naciones Unidas.

Bilbeny, Norbert. 2002. Por una causa común. Ética para La diversidad. Barcelona: Editorial Gedisa.

Bourdieu, Pierre. 1990. Sociología y cultura. México: Consejo Nacional para la Cultura y las Artes.

Chacón Marín, Luz María (comp.). 2010. Antología: Técnicas didácticas aplicables al trabajo de aula en las lecciones de Educación Religiosa. San José: Ministerio de Educación Pública, Instituto de Desarrollo Profesional Uladislao Gámez Solano.

Chávez Tortolero, Milagros. 2004. "La ética ambiental como reflexión en el marco de la educación en ciencias y en tecnología: Hacia el desarrollo de la conciencia de la responsabilidad". Educere, Universidad de los Andes, Mérida, Venezuela, vol. 8, núm. 27, octubre-diciembre: 483-488.

Facio, Alda. 2003. "Los derechos humanos desde una perspectiva de género y las políticas públicas". Otras miradas, Mérida, Venezuela, Universidad de los Andes, junio, año/vol. 3, número 001: 15-26.

Fornet-Betancourt, Raúl. 2001. Transformación Intercultural de la Filosofía. Bilbao: Desclée de Brouwer.

Hernández Freeman, Leopoldo. 2009. "La participación comunitaria como proceso sociocultural". Boletín Entre Lineas, Año III, No. 3-4, jul.-Dic.: 1-11.

Naciones Unidas. 1995. “A. Derechos reproductivos y salud reproductiva 7.2-7.11. Capítulo VII. Derechos reproductivos y salud reproductiva". Informe de la Conferencia Internacional sobre la Población y el Desarrollo. El Cairo, 5 a 13 de septiembre de 1994. Nueva York: Naciones Unidas: 37-48.

Riera, Carlos. 2005. "Presentación de las experiencias. Redes y comunidades". Martí, J., Pascual, J. y Rebollo, O. (coord.). Participación y desarrollo comunitario en medio urbano: experiencias y reflexiones. Madrid: IEPALA/CIMAS: 67-85. 
UNICEF/UDELAR. 2003. Nuevas formas de familia: Perspectivas nacionales e internacionales. Montevideo: UNICEF-UDELAR.

Vanier Institute of the Family. Definition of family. 2015. Web Canadá. Recuperado el 20/08/15 de: http://www.vanierinstitute. ca/definition_of_family_fr 
